\title{
Multi-instrument probing of the polar ionosphere under steady northward IMF
}

\author{
S. E. Pryse ${ }^{1}$, A. M. Smith ${ }^{1}$, L. Kersley ${ }^{1}$, I. K. Walker ${ }^{1}$, C. N. Mitchell ${ }^{1}$, J. Moen ${ }^{2} *$, R. W. Smith ${ }^{3}$ \\ ${ }^{1}$ Department of Physics, University of Wales, Aberystwyth, Ceredigion SY23 3BZ, UK \\ E-mail: sep@aber.ac.uk \\ ${ }^{2}$ AFRL/VSB (Space), Hanscom AFB, MA 01731-3010, USA \\ ${ }^{3}$ Geophysics Institute, University of Alaska-Fairbanks, AK99775, USA
}

Received: 23 February 1999 / Revised: 29 July 1999 / Accepted: 19 August 1999

\begin{abstract}
Observations are presented of the polar ionosphere under steady, northward IMF. The measurements, made by six complementary experimental techniques, including radio tomography, all-sky and meridian scanning photometer optical imaging, incoherent and coherent scatter radars and satellite particle detection, reveal plasma parameters consistent with ionospheric signatures of lobe reconnection. The optical green-line footprint of the reconnection site is seen to lie in the sunward plasma convection of the lobe cells. Downstream in the region of softer precipitation the reverse energy dispersion of the incoming ions can be identified. A steep latitudinal density gradient at the equatorward edge of the precipitation identifies the general location of an adiaroic boundary, separating the open field lines of polar lobe cells from the closed field of viscous-driven cells. Enhancements in plasma density to the south of the gradient are interpreted as ionisation being reconfigured as it is thrust against the boundary by the antisunward flow of the viscous cells near noon. Each of the instruments individually provides valuable information on certain aspects of the ionosphere, but the paper demonstrates that taken together the different experiments complement each other to give a consistent and comprehensive picture of the dayside polar ionosphere.
\end{abstract}

Key words. Ionosphere (polar ionosphere) ·

Magnetospheric physics (magnetosphere-ionosphere interactions; polar cap phenomena)

Correspondence to: S.E. Pryse

* On sabbatical leave from Arctic Geophysics, University Courses on Svalbard, N-9170 Longyearbyen, Norway

\section{Introduction}

The influence of the solar wind on the magnetosphere, and in turn the ionosphere, depends largely on the coupling between the interplanetary magnetic field (IMF) and the geomagnetic field. A major role is played by magnetospheric reconnection (Dungey, 1961) when the magnetic shear between the two fields is sufficiently large. For southward IMF, reconnection is most likely to occur in the vicinity of the equatorial plane. However, when the IMF is northward reconnection may take place at high latitude in the magnetospheric lobe. It follows that the orientation of the IMF has direct influence on the dynamics and structure of ionospheric plasma at auroral and polar latitudes.

For equatorial reconnection under steady-state, a twin vortex convection flow is established. There is antisunward plasma flow in the polar cap where the field lines are open and return sunward flows at lower latitudes in the dusk and dawn sectors on closed field lines. The dawn-dusk asymmetry depends on the $B y$ component of the IMF, with the tension force pulling newly opened field lines east or west depending on the sign of By (e.g. Cowley et al., 1991). The reconnection site is likely to map into the ionosphere equatorwards of the cusp, near the low-latitude edge of the antisunward flow in the noon sector (Lockwood, 1998). Middlealtitude observations of the signatures of reconnection have been observed in satellite particle measurements. Newell and Meng (1995) report the dispersion of ion energies, characteristic of equatorial reconnection, with energy decreasing with increasing latitude. High-latitude optical emissions accompanying particle precipitation have been studied extensively (Feldstein and Galperin, 1985 and references within). Fasel et al. (1993) interpreted multiple brightenings of dayside poleward-moving auroral forms in terms of flux transfer events (FTEs) with multiple X-line reconnection, while classification of different categories of dayside aurora according to IMF orientation was reported by Sandholt et al. (1998). An 
example of the spatial distribution of the ionospheric plasma consistent with low-latitude reconnection was presented by Walker et al. (1998) that was interpreted in terms of ion dispersion and the open/closed boundary of magnetic field lines. HF radars have been used to identify ionospheric features of the reconnection. Pinnock et al. (1995) observed FTEs that originated in the ionospheric footprint of the low-latitude boundary layer (LLBL) and were superposed on the background poleward flow-component.

Under northward IMF, or more specifically if the IMF clock angle is less than about $45^{\circ}$, magnetic reconnection may occur at lobe field lines. The associated high-latitude ionospheric flow patterns are depicted by Cowley (1998) in a figure adapted from earlier work by Reiff and Burch (1985). In contrast to the flows for equatorial reconnection, lobe reconnection results in sunward flow over the polar region and return flows at lower latitudes in the dawn and dusk sectors. The asymmetry around the noon meridian is again dependent on $B y$, with the dawn cell being enlarged for $B y>0$ and the dusk cell enlarged for $B y<0$. The open field lines of the lobe convection cells are separated by an adiaroic boundary from plasma circulating in the viscous cells on closed field lines at lower latitudes. The reconnection site in this case is believed to map into the sunward plasma flow of the polar cap (Lockwood, 1998). Optical signatures of lobe reconnection have been identified by Sandholt et al. (1996), while DMSP particle data reveal reverse ion dispersion with energy decreasing with decreasing latitude (Øieroset et al., 1997).

The present study is an investigation of observations made in the European sector near magnetic noon on the morning of 21 January, 1998, when $B z$ was strongly positive. The results presented focus on the time interval 0835-0925 UT. A tomographic image from this time period has been used by Pryse et al. (1999) to identify footprints of lobe reconnection in the spatial structure of the ionospheric ionisation. The current work extends the earlier study, and uses observations from six complementary experimental techniques to establish general ionospheric conditions over a prolonged period of steady northward IMF. The multi-instrument approach, based on radio tomography, optical, radar and satellite particle measurements, is essential for a comprehensive view of ionospheric behaviour.

\section{The interplanetary magnetic field}

The components of the IMF, measured by the WIND satellite between 07 and 09 UT on 21 January, 1998, are shown in the three panels of Fig. 1. The satellite was upstream in the solar wind, with co-ordinates of approximately $X \approx 232 R_{e}, Y \approx 14 R_{e}$ and $Z \approx-19 R_{e}$, where it measured an essentially constant solar wind speed of some $450 \mathrm{~km} \mathrm{~s}^{-1}$. The estimated delay in the response of the ionosphere to the measured IMF was about $1 \mathrm{~h}$ (Lockwood et al., 1989). Inspection of Fig. 1 shows that the IMF between 0735 and 0825 UT, the period of likely influence on the ionospheric observations, was steady in magnitude and with only minor
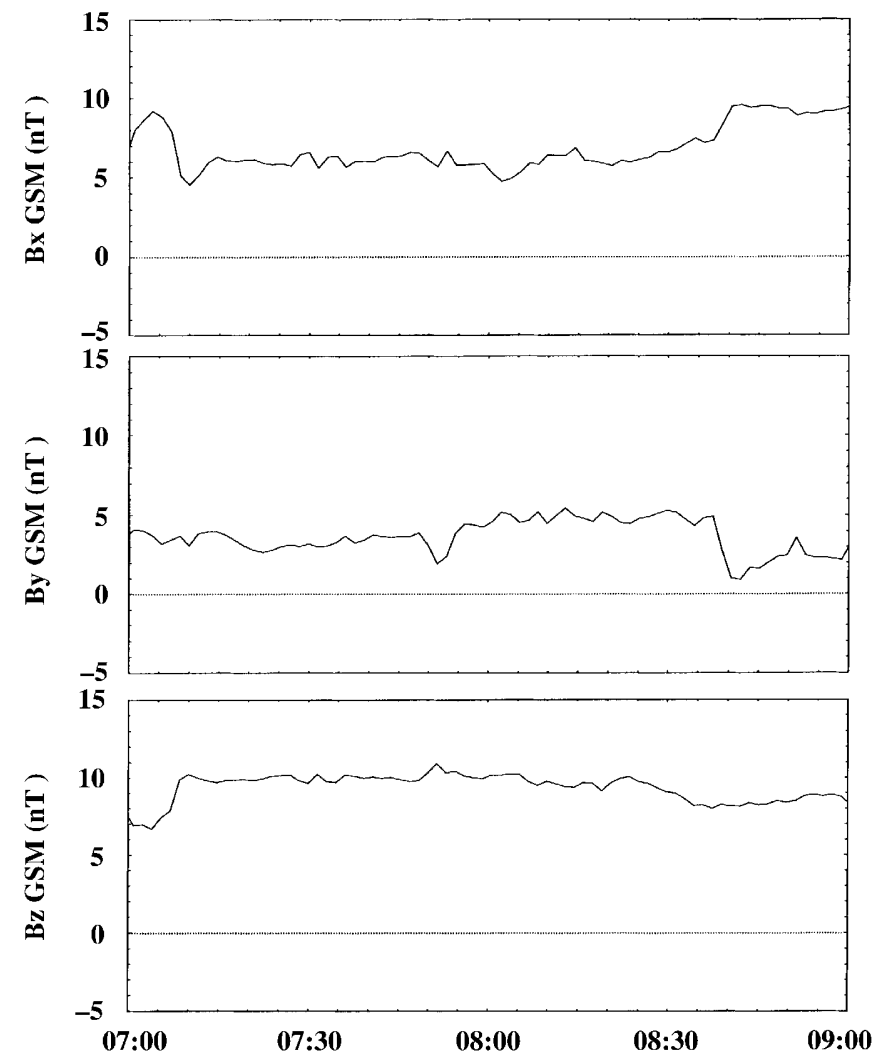

Fig. 1. $B x, B y$ and $B z$ components of the interplanetary magnetic field intensity measured by the WIND satellite between 07 and 09 UT on 21 January, 1998

fluctuations in the clock angle. $B z$ attained a value of $10 \mathrm{nT}$, which was maintained for most of the time interval of interest. $B y$ was also positive with values generally between 2 and $5 \mathrm{nT}$, as was $B x$. The clock angle for the period was less than $27^{\circ}$. Moreover, as this general IMF orientation had been in place since shortly after $07 \mathrm{UT}$, it is anticipated that the high-latitude convection flow was established by the time observations started and that it was maintained in steady-state throughout the period of interest. The orientation of $B z$ and $B y$ favoured lobe reconnection. However, $B x$ was positive, which is not the favoured condition for reconnection in the Northern Hemisphere (Crooker, 1992). Nevertheless, Øieroset et al. (1997) observed cusp aurora, that they take as signature of high-latitude reconnection, under both negative and positive $B x$, albeit with weak green emission for the latter.

\section{Observations}

\subsection{HF radar}

Observations of plasma flows during the time interval of interest were made by the HF Collaborative UK Superdarn radar (CUTLASS) with transmitters in Finland and Iceland. Figure 2 shows the line-of-sight velocities measured along the Finland radar beams at 


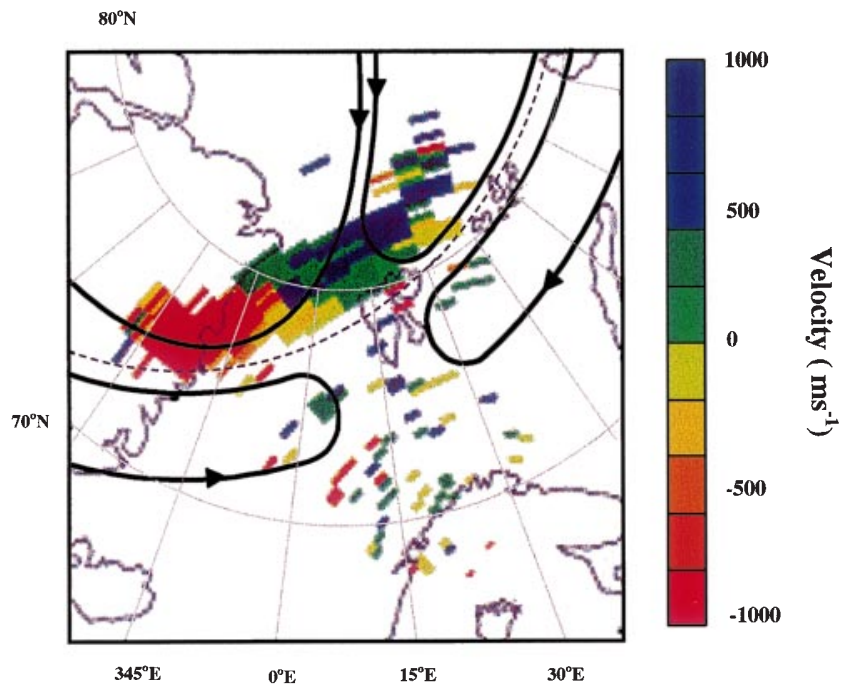

Fig. 2. Line-of-sight velocities measured by the Finland radar of the CUTLASS Superdarn facility at 0852 UT on a geographic grid. The positive values represent flows towards the radar and negative values flows away. Superimposed are flow stream lines (solid curves) and the adiaroic boundary (dashed curve) reminiscent of a portion of the Cowley (1998) pattern for the prevalent IMF conditions

0852 UT on a geographic co-ordinate grid. Unfortunately vector velocities were not available as no backscatter was recorded by the Iceland radar. The figure indicates the backscatter to be confined essentially to the north of Svalbard. Close inspection shows the lowlatitude boundary of the backscatter to be at approximately $76.3^{\circ} \mathrm{MLAT}$, intersecting $80^{\circ} \mathrm{N}, 20^{\circ} \mathrm{E}$. The component of the plasma drift along the beam is relatively strong and away from the radar on the western side of the field-of-view. It is towards the radar in the central beams, and away on the eastern side at the equatorward edge of signal return. The velocity components shown in the figure are typical of those observed by CUTLASS over an extended time period extending from 0830 to 0915 UT, after which the signal returns weaken but nevertheless still show signatures of the flow pattern until after 0925 UT. Superimposed on the figure are flow stream lines reminiscent of a portion of the Cowley (1998) flow pattern for the prevalent IMF conditions. The stream lines, depicted by the arrowed solid curves, show an enlarged dawn lobe cell and reduced dusk cell in accord with $B y>0$. The consistency of the measurements with the theoretically proposed flow pattern is clearly seen, in particular in the sunward cross-polar flow and the antisunward flows in the dusk and dawn sectors at the equatorward edges of the lobe cells and poleward sides of the viscous cells. The dashed arc on the figure separating the flows on the lobe cells from those of the viscous cells shows the approximate possible location of the adiaroic boundary across which there is no plasma-flow.

\subsection{All-sky camera}

Images of the $557.7 \mathrm{~nm}$ auroral emissions measured at 2 min intervals by the all-sky camera at Longyearbyen between 0841 and 0851 UT are shown in Fig. 3. These are also typical of observations over a wider time interval. The images are on a geographic co-ordinate grid, and show a distinct emission region centred generally near $80^{\circ} \mathrm{N}, 0^{\circ} \mathrm{E}\left(\sim 78.2^{\circ} \mathrm{MLAT}\right)$. Close inspection of the structure shows that it brightens and fades with a period of between 5 and $8 \mathrm{~min}$. Its location is taken to be indicative of the position of the ionospheric mapping of the reconnection site. Sporadic enhancements of intensity are observed over the south of Svalbard, with a steadily brightening feature at the extreme of the field-of-view.

\subsection{Meridian scanning photometer}

The observations of the all-sky camera are reinforced by the Meridian Scanning Photometer (MSP) of the Geophysical Institute, University of Alaska, Fairbanks, located at Longyearbyen. The instrument measures lineof-sight intensities of auroral emissions, as a function of elevation, as it scans essentially along the magnetic meridian with a total data acquisition time of $16 \mathrm{~s}$. Figure 4 shows the intensities of the $557.7 \mathrm{~nm}$ emission (right panel) and the $630.0 \mathrm{~nm}$ emission (left panel) from 0840 to $0910 \mathrm{UT}$, as a function of elevation measured from the northern horizon. The green-line observations, relating to energetic electrons $(\sim \mathrm{keV})$ that penetrate to E-layer altitudes, show a latitudinally narrow region of enhanced emission maximising at an elevation of about $15^{\circ},\left(80.3^{\circ} \mathrm{N}, 1.0^{\circ} \mathrm{E}, \sim 78.3^{\circ} \mathrm{MLAT}\right)$. This latitude relates to that of the high-latitude emission in the all-sky images. In the south of the field-of-view, at elevations greater than about $120^{\circ}$, the green emission shows a band of increased intensity. Whilst it is known that there was some cloud cover in this region of the sky, careful analysis revealed that the emission was seen through the cloud and possibly represented diffuse aurora originating from ring current precipitation. This may relate to the sporadic enhancements seen to the south of Svalbard in the all-sky images. The red line shows a broad band structure that arises from soft particle precipitation ( $\sim$ few hundreds of $\mathrm{eV}$ ) penetrating to F-region altitudes. As the emission can originate over a wide range of altitudes, it is not possible to be precise about the latitude range. However, the data are consistent with the possible interpretation that there was soft precipitation and $630 \mathrm{~nm}$ emission at $250 \mathrm{~km}$ to the south of the green-line arc.

\subsection{Ionospheric tomography}

The tomography chain of receivers operated by the University of Wales, Aberystwyth, comprises four stations in northern Scandinavia at $\mathrm{Ny}$ Alesund $\left(78.9^{\circ} \mathrm{N}, 12.0^{\circ} \mathrm{E}, 76.0^{\circ} \mathrm{MLAT}, 112.3^{\circ} \mathrm{MLON}\right)$, Longyearbyen $\left(78.2^{\circ} \mathrm{N}, 15.7^{\circ} \mathrm{E}, 75.1^{\circ} \mathrm{MLAT}, 113.0^{\circ} \mathrm{MLON}\right)$, Bjørnøya $\left(74.5^{\circ} \mathrm{N}, 19.0^{\circ} \mathrm{E}\right)$ and Tromsø $\left(69.8^{\circ} \mathrm{N}\right.$, $\left.19.0^{\circ} \mathrm{E}\right)$. These monitor the phase coherent signals from the polar orbiting satellites in the Navy Ionospheric 


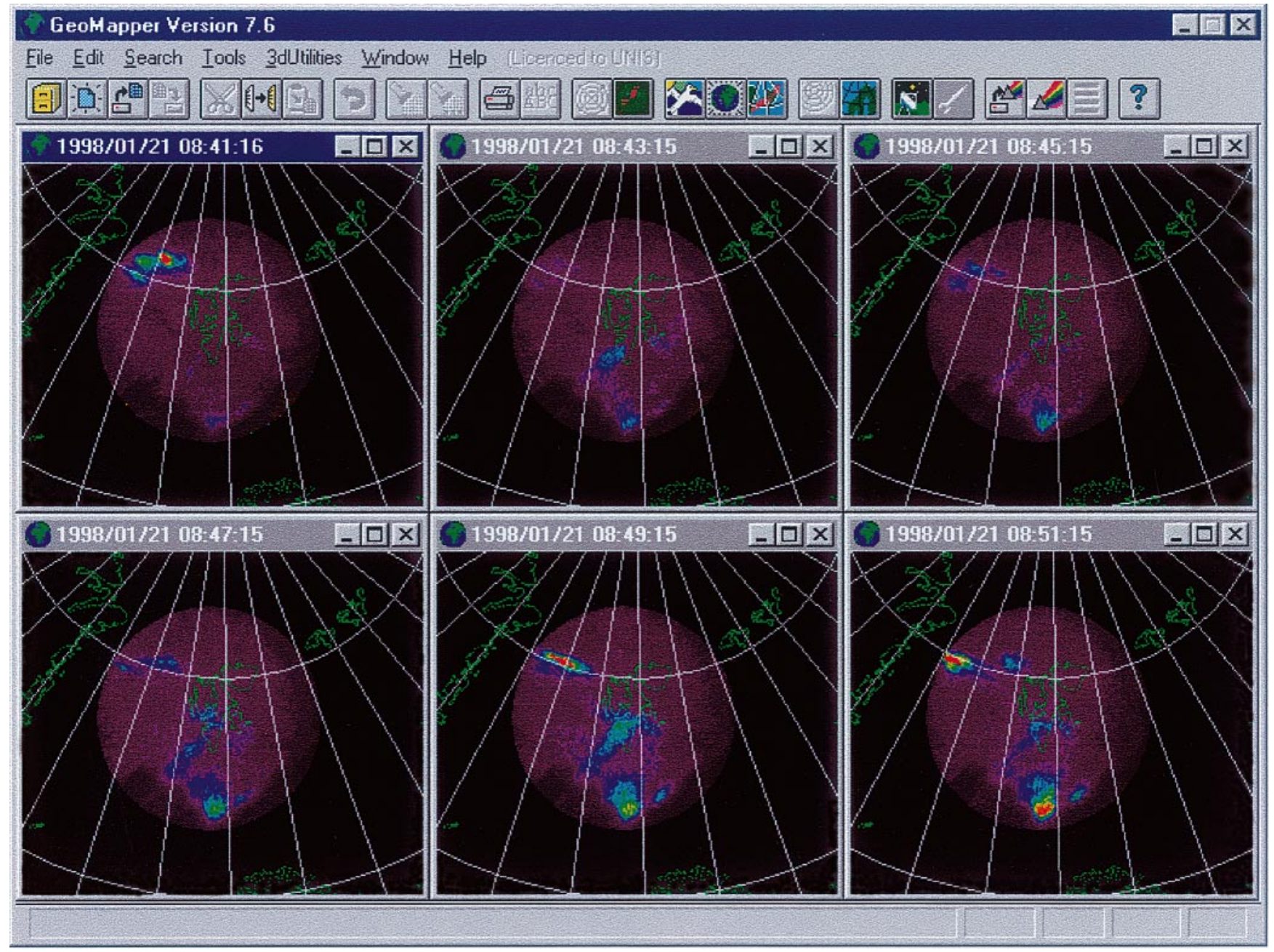

Fig. 3. Images from the all-sky camera located at Longyearbyen at 2 min intervals between 0841 and 0851 UT. The latitudinal scale shows $70^{\circ} \mathrm{N}$ and $80^{\circ} \mathrm{N}$, while the longitudinal scale is at intervals of $10^{\circ}$ with the centre line, that passes through Svalbard, marking $20^{\circ} \mathrm{E}$. The shaded circle shows the field-of-view of the camera
Monitoring System (NIMS), previously known as the Navy Navigational Satellite System (NNSS), and enable the measurement of total electron content along a large number of intersecting satellite-to-receiver ray-paths. Inversion of the data yields the distribution of electron density over a meridional section of the polar ionosphere (e.g. Walker et al., 1998; Moen et al., 1998). Figure 5 shows the plasma structure determined from a north-to-south satellite pass on the morning of 21 January, 1998 , with the satellite crossing latitude $75.0^{\circ} \mathrm{N}$ at 0845 UT. The trajectory, illustrated in Fig. 6 in terms of the magnetic co-ordinates of the $250 \mathrm{~km}$ intersection of the satellite-to-receiver ray paths, was essentially aligned along the noon magnetic meridian. The striking feature of the image (Fig. 5) is the sharp gradient near $79.5^{\circ} \mathrm{N}$, with densities decreasing abruptly to the north. The transition is borne out, not only near the peak of the F-region, but also at altitudes extending into the topside ionosphere as indicated by the height change in the $0.6 \times 10^{11}$ and $0.8 \times 10^{11} \mathrm{~m}^{-3}$ contours between 79.8 and $79.9^{\circ} \mathrm{N}$. The alignment of the feature with the geomagnetic field is not obvious at first sight. However, because of the offset of the path of the satellite to the east of the tomographic chain and the geometry of $L$ shells in the geographic co-ordinate system causing the geographic latitude of a shell to increase as it is traversed eastward, the magnetic field maps in a distorted manner into the tomographic plane. The line drawn along the maximum gradient indicates the position of the field line that intersects an altitude of $250 \mathrm{~km}$ at $76.2^{\circ}$ MLAT. The gradient is interpreted as being at the adiaroic boundary separating LLBL plasma on closed flux tubes from ionisation circulating on open magnetic flux in the polar lobe cells. The extension to high altitudes of the contours on the gradient may be indicative of upward moving electrons, constituting a downward Birkeland current that possibly links, through the ionospheric Eregion, to the upward current at the reconnection footprint. The F-region plasma distribution to the north of the gradient shows a slope in the height of the layer peak, with the altitude decreasing with increasing latitude between about 79.5 and $81.5^{\circ} \mathrm{N}$. It is consistent with the MSP red emission originating from soft precipitation. The gradient in peak height is interpreted 


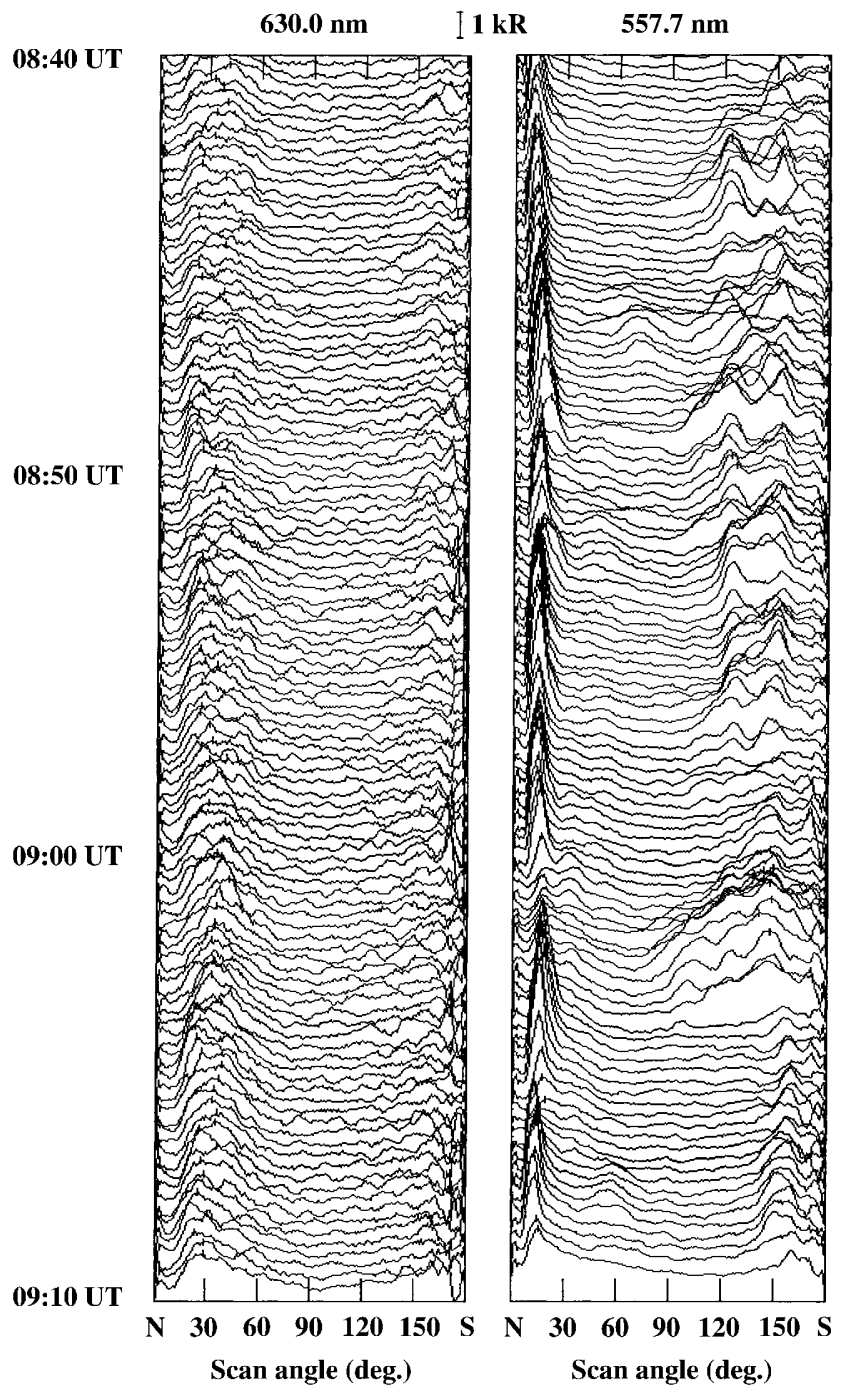

Fig. 4. Intensities of the $557.7 \mathrm{~nm}$ (right panel) and $630.0 \mathrm{~nm}$ (left panel) emissions observed by the MSP at Longyearbyen from 0840 to 0910 UT as a function of elevation measured from the northern horizon

as being reverse ion dispersion downstream of the ionospheric projection of the reconnection site. The faster ions which arrive first are the least displaced from the site and penetrate to the lower heights, while the less penetrating, slower species arrive slightly later in the ionosphere when the flux tubes have convected downstream. The expected E-region density enhancement at the reconnection footprint is not imaged in the tomographic reconstruction as poor geometrical coverage of the NIMS ray-path intersections at low altitudes well north of the most northerly receiver is not favourable for the imaging of the E-region density in this extreme latitudinal region of the field-of-view. A second satellite pass monitored some 20 min later also yielded an image showing the steep latitudinal density gradient (not shown). Close inspection demonstrated that this gradient was also aligned approximately along the field line that intersected an altitude of $250 \mathrm{~km}$ at $76.2^{\circ} \mathrm{MLAT}$.

\subsection{EISCAT Svalbard Radar}

Verification of the tomographic images is given by simultaneous EISCAT Svalbard Radar (ESR) observations. The radar beam was scanned in the magnetic meridian, symmetrically about the radar site, with a cycle time of $30 \mathrm{~min}$. The electron densities, electron temperatures, and line-of-sight ion drift velocities for the scan starting at 0829 UT are shown in Fig. 7. While the latitudinal range of the scan is more restricted than that of the tomography images and the resolution grid is poorer, there is broad agreement between the main features in the ionisation distribution, in particular the steep latitudinal gradient to the north of Longyearbyen. The electron temperatures show enhanced values to the north of the gradient, consistent with the ongoing soft-particle precipitation. The line-of-sight velocities reveal a tendency for F-region flows to be towards the radar over the entire field of view, with the exception of a narrow latitudinal band just north of the radar. Whilst some caution should be exercised in the interpretation of these velocity components, the pattern of sunward flows in the northernmost region of the field of view is consistent with the CUTLASS observations, and the overall trend, sunward flow in the north and poleward flow elsewhere, is generally consistent with the Cowley (1998) model for $B z>0$. The ion temperatures (not shown) did not show any distinctive features within the scan field-of-view.

\subsection{DMSP}

The F13 satellite of the Defence Meteorological Satellite Program (DMSP) followed an essentially east-to-west geomagnetic path, crossing the noon meridian near 0920 UT and reaching a maximum latitude of about $78.0^{\circ}$ MLAT (Fig. 6). Various regions of interest can be seen in the electron and ion spectra derived from the particle detectors aboard the satellite (Fig. 8). At the two extremities of the plot there are increased fluxes of $\mathrm{keV}$ electrons, mapping from the plasma sheet. Between 0917 UT and approximately 0922 UT the satellite was poleward of the plasma sheet boundary, in a region of an increased flux of soft electron precipitation. On either side within this central region, the ion spectrum shows the energy of the maximum flux increasing with latitude, indicative of reverse ion energy dispersion. The northern edges of the ion dispersion at 11.6 MLT and 12.4 MLT $\left(77.8^{\circ} \mathrm{MLAT}\right)$ indicate the poleward boundary of ion precipitation. Fluxes of electron precipitation are however found at higher latitudes, with an intensification of electrons at energies of $\sim \mathrm{keV}$ in the region immediately north of the ion dispersion. These may be indicative of an upward field-aligned current, as expected in the vicinity of the reconnection site. The latitude of the equatorward edge of the dispersion region is in accord with the magnetic latitude of the density gradient in the tomographic image and the soft, red-line precipitation indicated by the MSP.

The cross-track ion drifts for the DMSP pass are shown in Fig. 9. Unfortunately there is a gap in the data 


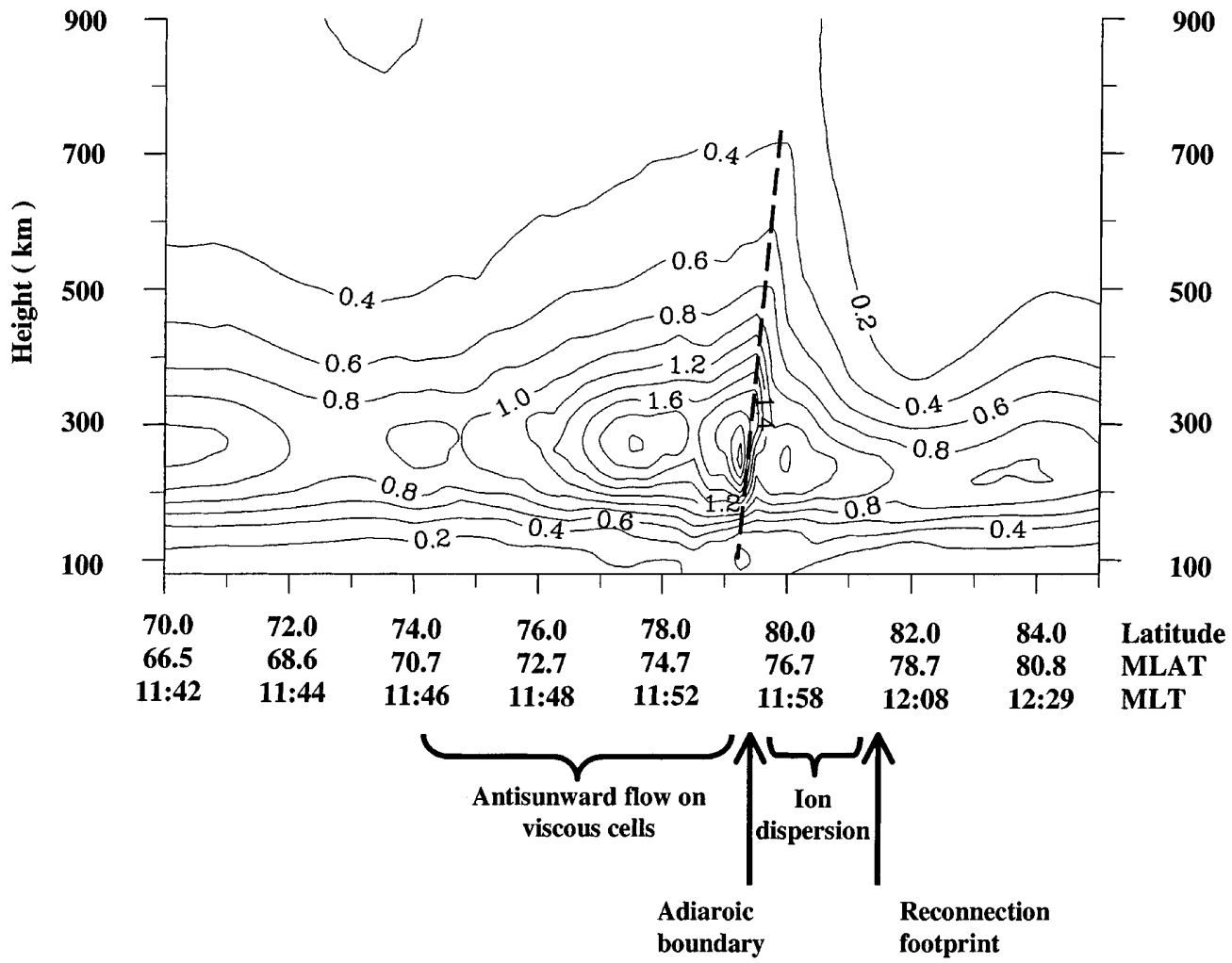

Fig. 5. Tomographic image obtained for the NIMS satellite pass at 0845 UT showing contours of electron density $\left(\mathrm{m}^{-3}\right)$. The dashed line indicates the position of the field line that intersects an altitude of $250 \mathrm{~km}$ at $76.2^{\circ} \mathrm{MLAT}$ between about 0919 and 0921 UT possibly due to low plasma densities. Nevertheless the horizontal drift measurements show clear indication of antisunward flow of several hundred $\mathrm{m} \mathrm{s}^{-1}$ on the afternoon side of the track ( 0918 UT), with sunward flow near magnetic noon (immediately prior to 0919 UT) and a substantial antisunward flow of some $2 \mathrm{~km} \mathrm{~s}^{-1}$ on the morning side (marginally later than 0921UT) that diminished in magnitude with decreasing MLT, consistent with the convection flow pattern illustrated in Fig. 2. The vertical

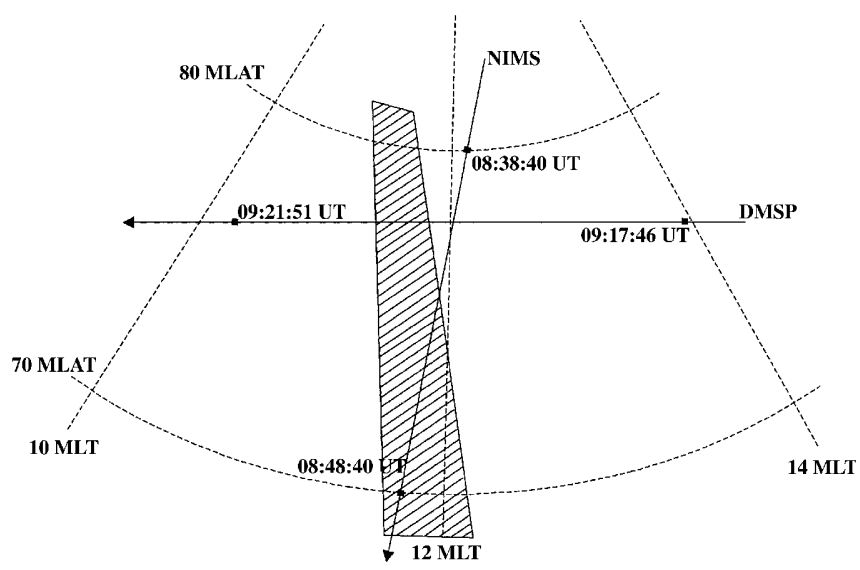

Fig. 6. Geometries of the NIMS satellite pass at 0845 UT and the DMSP pass at 0920 UT in a magnetic latitude versus MLT coordinate system. The trace for NIMS show the intersection of the satellite-to-receiver ray-paths with an altitude of $250 \mathrm{~km}$. The trace for DMSP shows the track at satellite-height. The hatched area shows the viewing region of the MSP at $250 \mathrm{~km}$ and above $15^{\circ}$ elevation between 0840 and 0910 UT drift was upward in the proximity of the proposed reconnection signature.

\section{Discussion and conclusions}

Observations from six independent experiments have been presented in a study of the northern high-latitude dayside ionosphere under steady IMF northward conditions. The steady coupling between the solar wind and magnetosphere was reflected by the consistency of the measurements over a time interval of almost $1 \mathrm{~h}$. Consistent signatures of the high-latitude reconnection were identified by each observing technique.

As in the study of Øieroset et al. (1997), the "type north" aurora was used as a likely signature of highlatitude reconnection. The mapping of the reconnection site to the ionosphere was identified by enhanced greenline emission observed by the all-sky camera and confirmed by MSP measurements. Signatures in the plasma distribution were identified in tomographic images, suggesting reverse ion energy dispersion equatorward of the reconnection site. The gradient in peak height, with height increasing with decreasing latitude, was in the opposite sense to that identified by Walker et al. (1998) under southward $B z$ when the cross-polar flow was expected to be antisunward. A steep gradient in electron density at about $76.2^{\circ}$ MLAT separated the polar region from lower latitudes, and is interpreted as representing the adiaroic wall generally marking the open/closed field-line boundary (Lockwood, 1998). This lies within the LLBL signature in the DMSP ion energy flux, suggesting that the northern part of the 

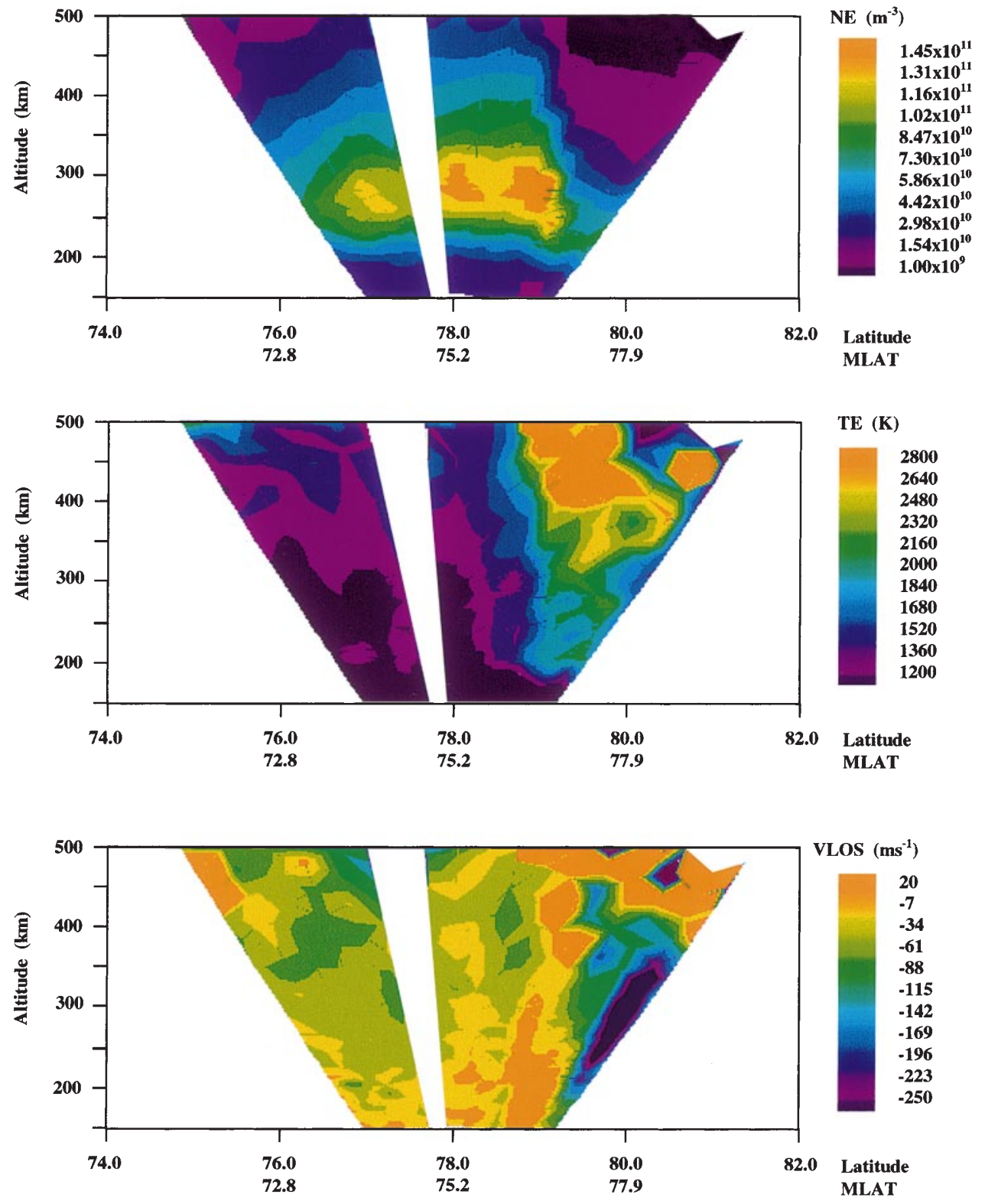

Fig. 7. Electron densities, electron temperatures and line-ofsight ion drift velocities measured by the ESR radar during a scan in the magnetic meridian starting at 0829 UT. Positive velocity values are away from the radar and negative towards
LLBL was on open field-lines and the southern part on closed field-lines. Confirmation of the gradient was provided by observations of electron density by the ESR radar. Radar measurements also supported the evidence for soft-precipitation, with elevated electron temperatures consistent with the red-line MSP emission. DMSP particle measurements were in support of the location of the reconnection signature, and identified reverse ion energy dispersion as the satellite traversed both towards and away from magnetic noon along its east-to-west trajectory. The satellite observations of the dispersion to both the east and west of noon, and by tomography close to the noon meridian suggest that the effect of the reconnection extended over a large spatial region. Such an extension in space is consistent with that of the final-state of the flow patterns presented by Øieroset et al. (1997), and based on Cowley and Lockwood (1992), in a sequence of figures relating to an IMF turning from $B z$ negative to positive. In their figure the dashed curves, which signify the loci of equal time intervals on streamlines downstream of the reconnection site, showed how the flux tubes emerged at the southern side of the reconnection site and spread-out sunward, and subsequently dawnward and duskward, in accord with the direction of the cross-polar plasma flow.

At latitudes south of that identified for the adiaroic boundary, the DMSP observations suggest the presence of harder-particle precipitation consistent with the diffuse ring current aurora seen by the MSP. The tomographic images contain some limited evidence of increased ionisation density in the E-region near the latitudes of the northern receivers caused by hard precipitation. Both the tomographic images and the ESR revealed structured F-layer densities immediately equatorward of the boundary. It is possible that this 
F13 21 Jan 1998

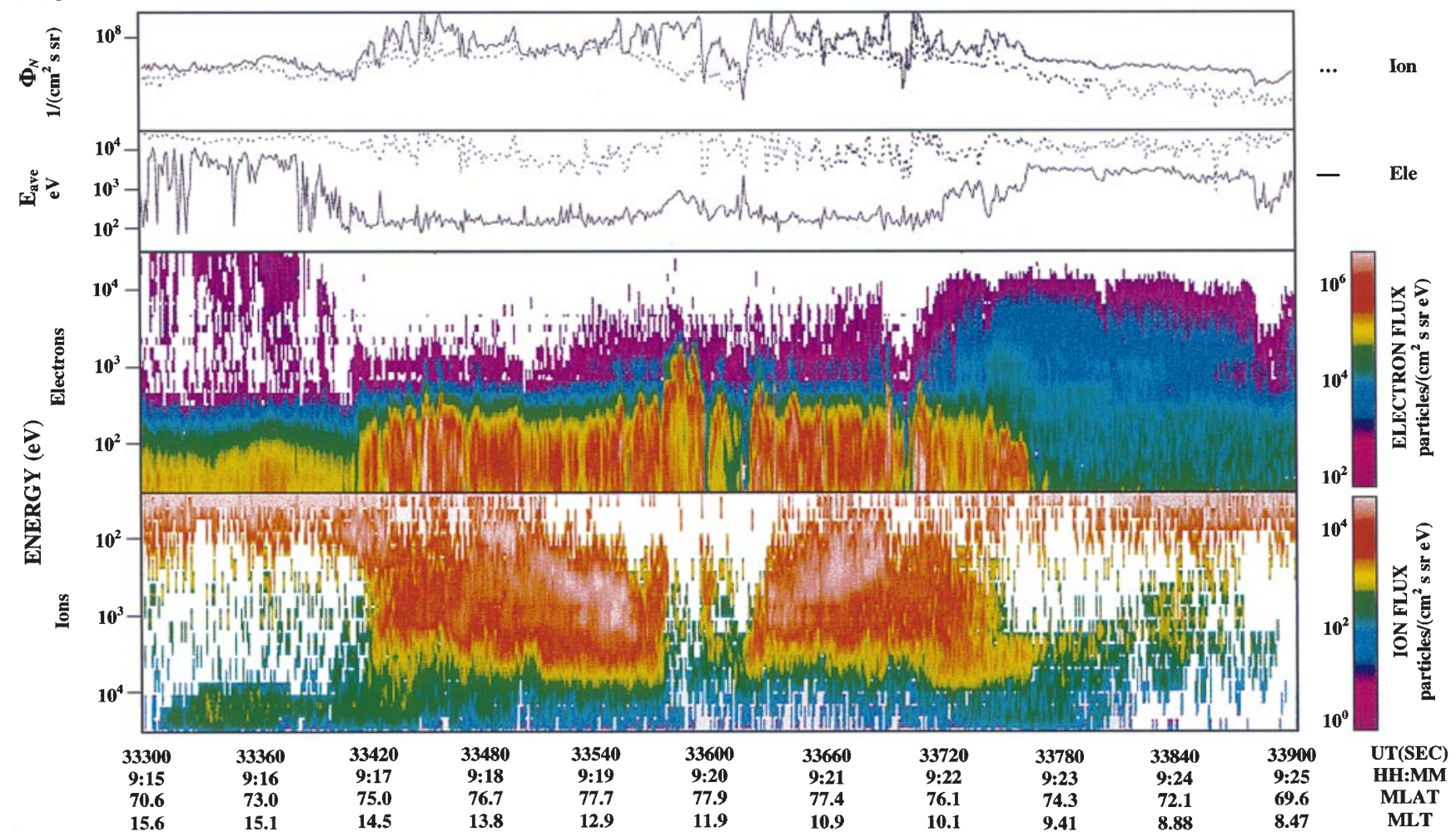

Fig. 8. Electron and ion fluxes measured during the DMSP satellite pass at 0920 UT

long-lived F-layer ionisation was not produced locally, but may have been convected along the southern edges of the viscous cells. The build-up of ionisation on the southern side of the adiaroic boundary could then have been caused by the northward motion near noon on the viscous cells with the plasma being reconfigured as it was thrust against the wall.

In conclusion, the results presented from six different experimental techniques show consistent observations of the day-side polar ionosphere under steady northward
$B z$ with small clock angle. While signatures of the reconnection, summarised in Fig. 5, have been observed in previous studies by individual instruments, the current work highlights the complementary roles of HF radar, optical all-sky, MSP, radio tomography, ESR and satellite particle data. Taken together, the chain of ionospheric responses to the northward IMF and lobe reconnection can be followed from the reconnection site through the ion dispersion region to the adiaroic boundary.

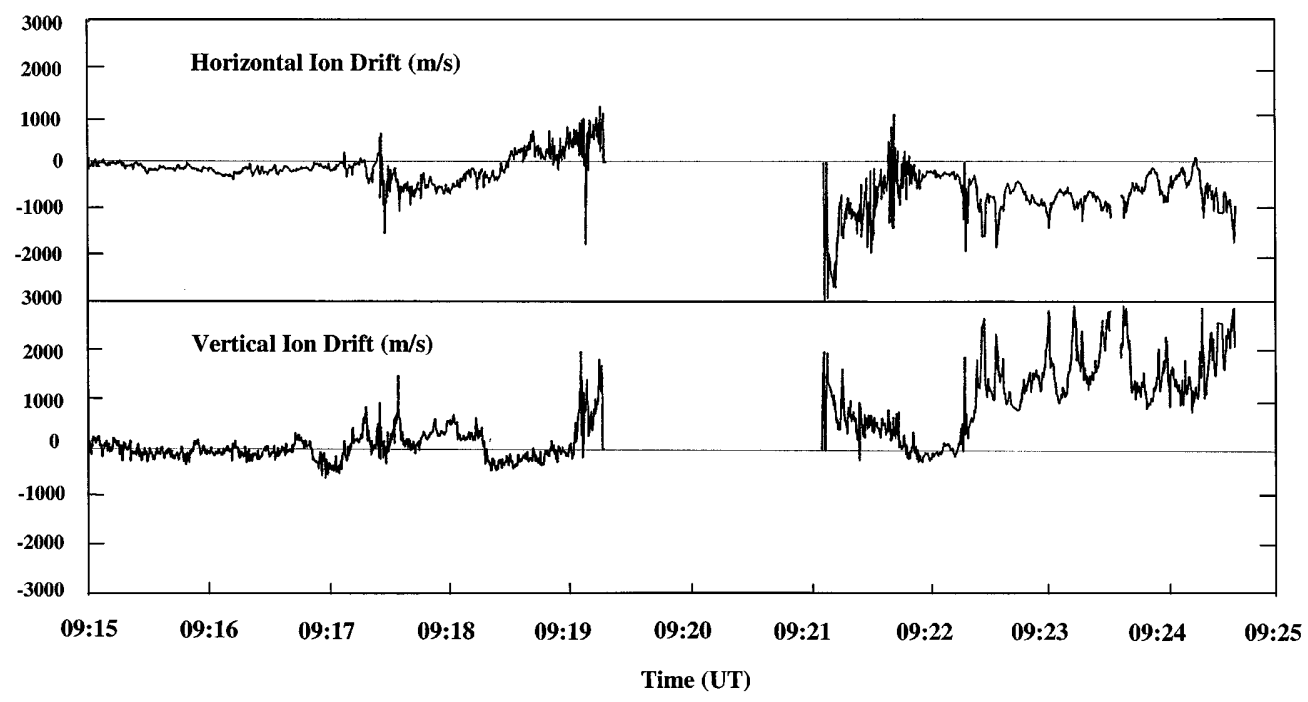

Fig. 9. Horizontal (top panel) and vertical (lower panel) ion drift velocities measured during the DMSP satellite pass at $0920 \mathrm{UT}$ 
Acknowledgements. Financial support for the project has been provided by the UK Particle Physics and Astronomy Research Council under grant PPA/G/S/1997/00269 and the Norwegian Research Council and UNIS under grant 9/963. The assistance of the University of Tromsø and the Norwegian Polar Research Institute in the tomographic measurements is gratefully acknowledged. The DMSP data were provided by F. Rich at AFRL, Hanscom, USA. The CUTLASS radar is a UK national facility funded by the Particle Physics and Astronomy Research Council; the data used here have been supplied by M. Lester. EISCAT is an international facility supported by the national science councils of Finland, France, Germany, Japan, Norway, Sweden and the United Kingdom. The WIND data were provided by R. Lepping at NASA/GSFC.

The Editor-in-chief thanks D. A. Lorentzen and F. Socaas for their help in evaluating this paper.

\section{References}

Cowley, S. W. H., Excitation of flow in the Earth's magnetosphereionosphere system: observations by incoherent scatter radar, in Polar Cap Boundary Phenomena, Eds. J. Moen et al., NATO Advanced Study Institute Series, Kluwer Academic Press, Dordrecht, The Netherlands, 509, 127-140, 1998.

Cowley, S. W. H., and M. Lockwood, Excitation and decay of solar wind-driven flows in the magnetosphere-ionosphere system, Ann. Geophysicae, 10, 103-115, 1992.

Cowley, S. W. H., J. P. Morelli, and M. Lockwood, Dependence of convective flows and particle precipitation in the high-latitude dayside ionosphere on the $\mathrm{X}$ and $\mathrm{Y}$ components of the interplanetary magnetic field, J. Geophys. Res., 96, 5557-5564, 1991.

Crooker, N. U., Reverse convection, J. Geophys. Res., 97, 19,36319,372, 1992.

Dungey, J. W., Interplanetary magnetic field and the auroral zones, Phys. Rev. Lett., 6, 47-48, 1961.

Fasel, G. J., L. C. Lee, and R. W. Smith, A mechanism for the multiple brightenings of dayside poleward-moving auroral forms, Geophys. Res. Lett., 20, 2247-2250, 1993.

Feldstein, Y. I., and Yue. I. Galperin, The auroral luminosity structure in the high-latitude upper atmosphere: its dynamics and relationship to the large-scale structure of the Earth's magnetosphere, Rev. Geophys., 23, 217-275, 1985.

Lockwood, M., Identifying the open-closed field line boundary, in Polar Cap Boundary Phenomena, Eds. J. Moen et al., NATO Advanced Study Institute Series, Kluwer Academic Press, Dordrecht, The Netherlands, 509, 73-90, 1998.

Lockwood, M., P. E. Sandholt, S. W. H. Cowley, and T. Oguti, Interplanetary magnetic field control of dayside auroral activity and the transfer of momentum across the dayside magnetopause, Planet. Space Sci., 37, 1347-1365, 1989.

Moen, J., S. T. Berry, L. Kersley, and B. Lybekk, Probing discrete auroral arcs by ionospheric tomography, Ann. Geophysicae, 16, 574-582, 1998.

Newell, P. T., and C.-I. Meng, Cusp low-energy ion cutoffs: a survey and implications for merging, J. Geophys. Res., 100, 21,943-21,951, 1995.

Øieroset, M., P. E. Sandholt, W. F. Denig, and S. W. H. Cowley, Northward interplanetary magnetic field cusp aurora and highlatitude magnetopause reconnection, J. Geophys. Res., 102, 11,349-11,362, 1997.

Pinnock, M., A. S. Rodger, J. R. Dudeney, F. Rich, and K. B. Baker, High spatial and temporal resolution observations of the ionospheric cusp, Ann. Geophysicae, 13, 919-925, 1995.

Pryse, S. E., A. M. Smith, J. Moen, and D. A. Lorentzen, Footprints of lobe reconnection observed in ionospheric electron density under steady northward IMF, Geophys. Res. Lett., 26, 25-28, 1999.

Reiff, P. H., and J. L. Burch, IMF By-dependent plasma flow and Birkeland currents in the dayside magnetosphere: 2. A global model for northward and southward IMF, J. Geophys. Res., 90, 1595-1609, 1985.

Sandholt, P. E., C. J. Farrugia, M. Øieroset, P. Stauning, and S. W. H. Cowley, Auroral signature of lobe reconnection, Geophys. Res. Lett., 23, 1725-1728, 1996.

Sandholt, P. E., C. J. Farrugia, J. Moen, and B. Lybekk, The dayside aurora and its regulation by the interplanetary magnetic field, in Polar Cap Boundary Phenomena, Eds. J. Moen et al., NATO Advanced Study Institute Series, Kluwer Academic Press, Dordrecht, The Netherlands, 509, 189-208, 1998.

Walker, I. K., J. Moen, C. N. Mitchell, L. Kersley, and P. E. Sandholt, Ionospheric effects of magnetopause reconnection observed using ionospheric tomography, Geophys. Res. Lett., 25, 293-296, 1998. 